\title{
Comparison of ultrasound and cineangiographic measurements of left ventricular performance in patients with and without wall motion abnormalities ${ }^{1}$
}

\author{
Philip Ludbrook, Joel S. Karliner, Kirk Peterson, George Leopold, and Robert A. O'Rourke \\ From the Cardiovascular Division, Department of Medicine, and the Department of Radiology, University of \\ California, La folla, California 92037, U.S.A.
}

It has been proposed that ultrasound estimation of left ventricular volume, ejection fraction, and the mean rate of circumferential fibre shortening (mean $V_{\mathrm{CF}}$ ) may be inaccurate in patients with abnormalities of left ventricular wall motion. Accordingly, we measured left ventricular dimensions by echocardiography in 36 patients undergoing biplane left ventricular cineangiography, 2 I of whom had an abnormal pattern of left ventricular wall motion. In 19 instances this was due to coronary artery disease and in 2 cases to primary myocardial disease. In the 15 patients with normal wall motion, the end-diastolic volume corrected for body surface area (end-diastolic volume index) was normal in all but one instance by both echo and cine, while in the group with abnormal wall motion, 8 had an enlarged end-diastolic volume index measured by both techniques, and ro were normal by both methods; in 3 patients the measurements were discordant. With the exception of 4 patients with abnormal wall motion and I with normal wall motion, the ultrasound method separated those patients with a normal from those with a reduced ejection fraction. By contrast, all patients with wall motion abnormalities had depressed left ventricular performance as judged by the mean rate of circumferential fibre shortening (mean $V_{\mathrm{CF}}$ ) calculated either by cineangiography or by echocardiography. We conclude that echographic assessment of left ventricular volume may be subject to error in individual patients, especially those with an enlarged left ventricular chamber in whom conventional assumptions regarding the ellipsoid shape of the normal left ventricular cavity may not be valid. However, calculation of ejection-phase measures of left ventricular performance, especially mean $V_{\mathrm{CF}}$, the estimation of which does not require any assumptions regarding left ventricular cavity size or shape appears to be valid even in the presence of disordered left ventricular wall motion.

Recent reports have confirmed the usefulness of ultrasound echocardiography for the measurement of left ventricular dimensions (Popp et al., 1969), ejection fraction (Pombo, Troy, and Russell, 197I), and the mean rate of circumferential fibre shortening (mean $\mathrm{V}_{\mathrm{CF}}$ ) (Cooper et al., 1972). Close correlations have been demonstrated between these echographic estimations of left ventricular performance and their cineangiographic counterparts both in normal subjects and in patients with left ventricular disease. However, it is possible that ultrasound techniques entailing examination of small areas of the anterior and posterior ventricular walls may not be applicable in patients with disordered patterns of wall motion. For example, the Received 3 May I973.

1 Supported in part by a U.S. Public Health Service Program Project Grant, and the National Heart Foundation of Australia (Dr. Ludbrook). calculation of ventricular volumes is usually based on theoretical elliptical or spherical models, and these may not apply in the presence of abnormal wall motion which tends to distort left ventricular geometry (Teichholz et al., 1972; Popp et al., 1973). Accordingly, we have examined the influence of left ventricular wall motion abnormalities on the reliability of left ventricular volume, ejection fraction, and mean $\mathrm{V}_{\mathrm{CF}}$ obtained by echocardiography, as compared with similar measurements made from biplane left ventricular cineangiograms.

\section{Subjects and methods}

Thirty-six patients, 29 men and 7 women, admitted for diagnostic cardiac catheterization and coronary arteriography, were studied. The average age for all 36 patients was 50 years (range 28 to 66 years). The mean age for the group of 15 patients with normal wall motion was 46 
years (range 28 to 60 ) and for the 21 with abnormal wall motion, 56 years (range 40 to 66 ). In all of the 21 patients in whom inspection of the left ventriculogram revealed an abnormal pattern of left ventricular wall motion, cardiac performance was judged to be abnormal by I or more of the following haemodynamic criteria: resting left ventricular end-diastolic pressure greater than I2 $\mathrm{mmHg}$; cardiac index less than $2.51 . / \mathrm{min}$ per $\mathrm{m}^{2}$; and ejection fraction of less than 0.52 (Dodge et al., I966). Significant coronary artery disease was observed in 19 of these patients; in the remaining 2, primary myocardial disease was diagnosed. In ro patients, akinetic areas were present at the anterior and/or lateral left ventricular surface, while in 3 patients hypokinesis was noted at these surfaces. In 5 other patients, diffuse hypokinesis was present, while in 2 further patients, the apical and/or inferior surfaces alone were akinetic.

Of the 15 patients in whom a normal pattern of left ventricular wall motion was observed, cardiac performance was judged to be normal in 13 by the criteria mentioned above; in the remaining 2 patients, the left ventricular end-diastolic pressure at rest was mildly raised. Significant coronary artery disease was present in 7 of these patients, while billowing mitral leaflets were observed in 3. The remaining 5 patients were considered to be free of cardiovascular disease.

Cardiac catheterization was performed in the postabsorptive state, after premedication with $100 \mathrm{mg}$ pentobarbitone sodium given intramuscularly. All patients were in sinus rhythm at the time of study. Left ventricular catheterization was performed by the retrograde arterial technique, and biplane left ventricular cineangiograms were recorded at 75 frames/sec after the intraventricular injection of $40-50 \mathrm{ml} 75$ per cent sodium diatrizoate over a 2 to $3 \mathrm{sec}$ period. All beats analysed represented ventricular contractions originating from normal electrical depolarization, and none was preceded by extrasystoles. End-systolic and end-diastolic left ventricular volumes were obtained by the area-length method for biplane ventriculograms (Dodge et al., 1960) and the ejection fraction calculated from these measurements (Dodge et al., 1966). The mean velocity of circumferential fibre shortening [mean $\mathrm{V}_{\mathrm{CF}}$ ] was derived from the lateral projection of the left ventriculogram by calculating the shortening of a chord drawn perpendicular to the long axis of the ventricle at one-third the distance from the midpoint of the mitral valve plane to the cardiac apex. This chord was selected for comparison, since it corresponds most closely to the plane of the ultrasound beam (Cooper et al., 1972). The extent of shortening was divided by the ejection time, and this result in turn normalized for end-diastolic circumference, and the result expressed in circumference (circ)/sec (Karliner et al., I97I). This method enables comparison among patients.

Methods of echocardiographic measurement of left ventricular performance have previously been described in detail (Cooper et al., 1972). A commercially available ultrasonoscope (Ekoline 20, Mark II, Smith-Kline) was employed, using a $2.25 \mathrm{mHz}, 1.9 \mathrm{~cm}$ unfocused transducer with a repetition rate of I000 impulses per second. The standard technique of examining a hypothetical chord through the minor diameter of the base of the left ventricle was followed. Anteriorly, ultrasound reflections were obtained from the interventricular septal endocardium, and posteriorly from the opposed area of posterior wall endocardium immediately inferior to the mitral valve echo (Fig. I). Careful visualization of the ' $x$ ' line, representing echoes from the mitral valve supporting apparatus, ensured both accurate definition of left ventricular endocardium and consistent localization of the ultrasound beam. Polaroid photographs of the 'time-motion' echo display were recorded directly from the oscilloscope face. In each case, end-diastolic and end-systolic volumes were calculated by the cube method (Pombo et al., 197I), using the average of 5 beats. Ejection fraction and mean $\mathrm{V}_{\mathrm{CF}}$ were also calculated using previously described methods (Fig. I) (Cooper et al., 1972). All ultrasound examinations were performed in the supine basal state within 24 hours of cardiac catheterization. Previous studies from this laboratory have shown that echo mean $V_{C F}$ by this technique is reproducible within 6 per cent (Cooper et al., 1972).

\section{End-diastolic volume \\ Results}

In the I5 subjects with normal wall motion, enddiastolic volume, calculated by echo averaged I46 \pm 49 ( \pm I SD) $\mathrm{ml}$, and by cine I I $\pm 36 \mathrm{ml}$, while in the $2 \mathrm{I}$ patients with abnormal wall motion echo end-diastolic volume averaged $227 \pm 91 \mathrm{ml}$, and the average by cine was $201 \pm 88 \mathrm{ml}$ (Table, Fig. 2, left panel). In Fig. 2, the two points lying outside the 95 per cent confidence limits represent two patients with severe anterior akinesis. In the patients with larger volumes, a greater difference was seen between the echographic and cineangiographic measurements. Despite these discrepancies in individual patients, however, there was a highly significant correlation between these two measurements for the whole group ( $r=0.85, \mathbf{P}<0.0001)$, and if only the group with wall motion abnormalities is considered, the $\mathrm{r}$ value was $0.83(\mathbf{P}<0.000 \mathrm{I})$.

\section{End-diastolic volume index}

In the I5 patients with normal wall motion, enddiastolic volume index estimated by echo averaged $79 \pm 22 \mathrm{ml} / \mathrm{m}^{2}$ and by cine $65 \pm 20 \mathrm{ml} / \mathrm{m}^{2}$, while in the 2 I patients with abnormal wall motion the echographic estimate averaged $125 \pm 53 \mathrm{ml} / \mathrm{m}^{2}$ compared with the cine value of I I I $\pm 50 \mathrm{ml} / \mathrm{m}^{2}$ (Table, Fig. 2, right panel). A very high degree of concordance was seen in the group with normal wall motion, all but I of whom had a normal end-diastolic volume index measured by either method. In the group with abnormal wall motion, 8 had an enlarged end-diastolic volume index measured by both techniques. In 3 other patients with abnormal wall motion, however, 


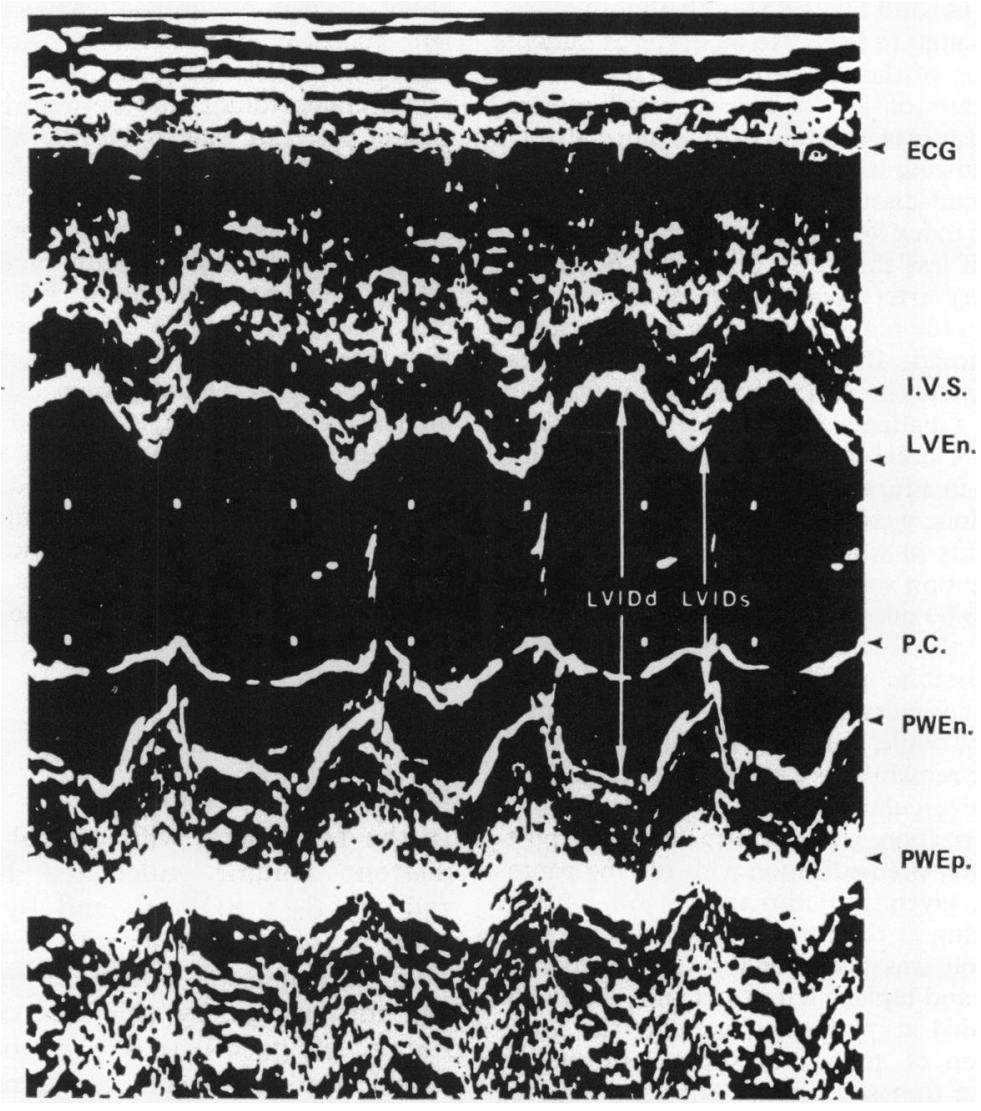

FIG. I An echocardiogram which shows the left ventricular endocardial surface (LVEn.) of the intraventricular septum (I.V.S.), and the left ventricular posterior wall endocardium (PWEn.) is illustrated. Careful visualization of the posterior chordae (P.C.) ensured both accurate definition of the left ventricular endocardium and consistent localization of the ultrasound beam. Automatically incorporated into the display are the simultaneous electrocardiogram (ECG) and timedistance markers. Distance is plotted on the ordinate and time on the abscissa. The left ventricular internal end-diastolic dimension (LVIDd) between endocardial surfaces was measured along a vertical line drawn through the $Q R S$ complex. The left ventricular internal end-systolic dimension (LVIDs) was defined as the smallest distance separating the endocardial surfaces of the septum and the left ventricular posterior wall. Ejection time was taken as the length of time from the peak of the QRS complex to the maximum excursion of the left ventricular posterior wall, less 50 msec for the pre-ejection period when no appreciable fibre shortening occurs (Karliner et al., I97I).

the 2 measurements were discordant (Fig. 2, right panel, right lower and left upper quadrants). However, for the entire patient group there was a highly significant correlation between these 2 estimates $(\mathrm{r}=0.86, \mathrm{P}<0.000 \mathrm{I})$.

\section{Ejection fraction}

In the 15 patients with normal wall motion, the ejection fraction averaged $0.66 \pm 0.09$ measured by ultrasound, and $0.67 \pm 0.09$ by cineangiography. In the 2 I patients with abnormal wall motion, echo measurement of the ejection fraction averaged $0.44 \pm 0.12$, while cine ejection fraction averaged $0.39 \pm 0.13$ (Table, Fig. 3). With the exception of 5 patients with abnormal wall motion, and I with normal wall motion, the ultrasound method separated those patients with normal from those with a reduced ejection fraction (Fig. 3). For the whole 
TABLE Left ventricular dimensions, ejection fraction, and mean $V_{C F}$ in patients with normal and abnormal left ventricular wall motion

\begin{tabular}{|c|c|c|c|c|c|c|c|c|}
\hline & \multicolumn{3}{|c|}{ Normal } & \multicolumn{3}{|c|}{ Abnormal } & \multirow{2}{*}{$\begin{array}{l}\text { Statistical differences } \\
\text { between patients } \\
\text { with normal and } \\
\text { abnormal LV } \\
\text { wall motion }\end{array}$} & \multirow{2}{*}{$\begin{array}{l}\text { Correlations } \\
\text { for total } \\
\text { patient population } \\
(N=36)\end{array}$} \\
\hline & $\begin{array}{l}L V w a \\
(N=I S\end{array}$ & $\begin{array}{l}\text { all motion } \\
\text { 5) }\end{array}$ & Correlation & $\begin{array}{l}L V w c \\
(N=2\end{array}$ & all motion & Correlation & & \\
\hline $\begin{array}{l}\text { LV } \\
\text { end-diastolic } \\
\text { volume (ml) } \\
\text { LV } \\
\text { end-diastolic } \\
\text { volume index } \\
\left(\mathrm{ml} / \mathrm{m}^{2}\right)\end{array}$ & $\begin{array}{l}\text { Echo } \\
\text { Cine } \\
\text { Echo } \\
\text { Cine }\end{array}$ & $\begin{array}{l}146 \pm 49^{\star} \\
117 \pm 36 \\
79 \pm 22 \\
65 \pm 20\end{array}$ & $\begin{array}{l}r=0.70 \\
P<0.01 \\
r=0.54 \\
P<0.05\end{array}$ & $\begin{array}{l}\text { Echo } \\
\text { Cine } \\
\text { Echo } \\
\text { Cine }\end{array}$ & $\left.\begin{array}{l}227 \pm 91^{\star} \\
201 \pm 88 \\
125 \pm 53 \\
111 \pm 50\end{array}\right\}$ & $\begin{array}{l}r=0.83 \\
P<0.000 I \\
r=0.86 \\
P<0.00 I\end{array}$ & $\begin{array}{l}P<0.001 \\
P<0.001 \\
P<0.01 \\
P<0.001\end{array}$ & $\begin{array}{l}r=0.85 \\
P<0.000 I \\
r=0.86 \\
P<0.000 I\end{array}$ \\
\hline $\begin{array}{l}\text { LV } \\
\text { ejection } \\
\text { fraction } \\
\text { Mean } \\
\mathrm{V}_{\mathrm{CF}} \dagger \\
\text { (circ./sec) }\end{array}$ & $\begin{array}{l}\text { Echo } \\
\text { Cine } \\
\text { Echo } \\
\text { Cine }\end{array}$ & $\begin{array}{l}0.66 \pm 0.09 \\
0.67 \pm 0.09 \\
1 \cdot 26 \pm 0.24 \\
1.64 \pm 0.55\end{array}$ & $\left\{\begin{array}{l}r=0.64 \\
P<0.01 \\
r=0.6 I \\
P<0.05\end{array}\right.$ & $\begin{array}{l}\text { Echo } \\
\text { Cine } \\
\text { Echo } \\
\text { Cine }\end{array}$ & $\left.\begin{array}{l}0.44 \pm 0.12 \\
0.39 \pm 0.13 \\
0.67 \pm 0.21 \\
0.65 \pm 0.23\end{array}\right\}$ & $\left\{\begin{array}{l}r=0.67 \\
P<0.01 \\
r=0.63 \\
P<0.01\end{array}\right.$ & $\begin{array}{l}P<0.001 \\
P<0.001 \\
P<0.001 \\
P<0.001\end{array}$ & $\begin{array}{l}r=0.84 \\
P<0.000 I \\
r=0.84 \\
P<0.000 I\end{array}$ \\
\hline
\end{tabular}

* Values represent group mean \pm I standard deviation.

$\dagger$ Mean velocity of circumferential fibre shortening.
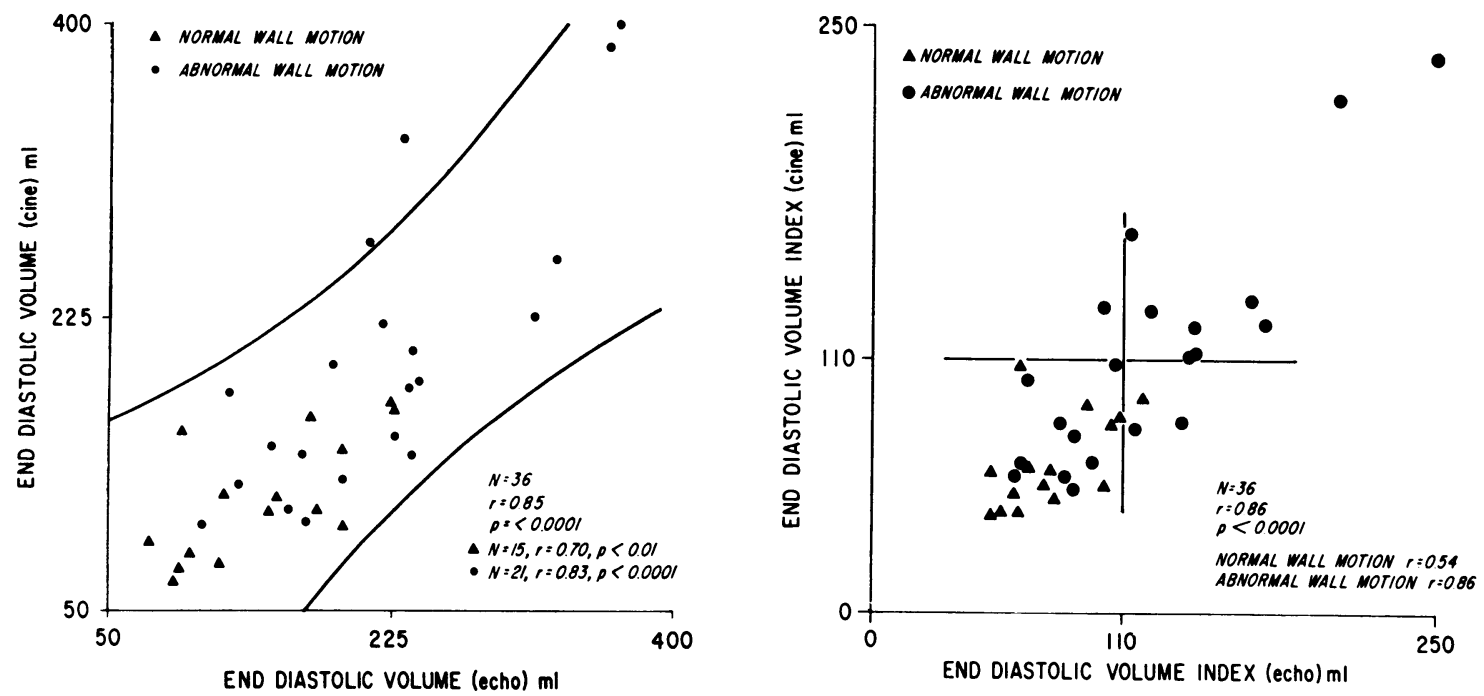

FIG. 2 Left panel. The plot between cine and echo end-diastolic volume is depicted. The curved lines represent the 95 per cent confidence limits for this relation. The two points lying outside the upper limit represent 2 patients with severe anterior wall dyskinesis.

Right panel. The relation between cine and echo end-diastolic volume corrected for body surface area demonstrates a significant correlation. The crossed lines represent the upper limit of normal for this measurement (Kennedy et al., 1966). 


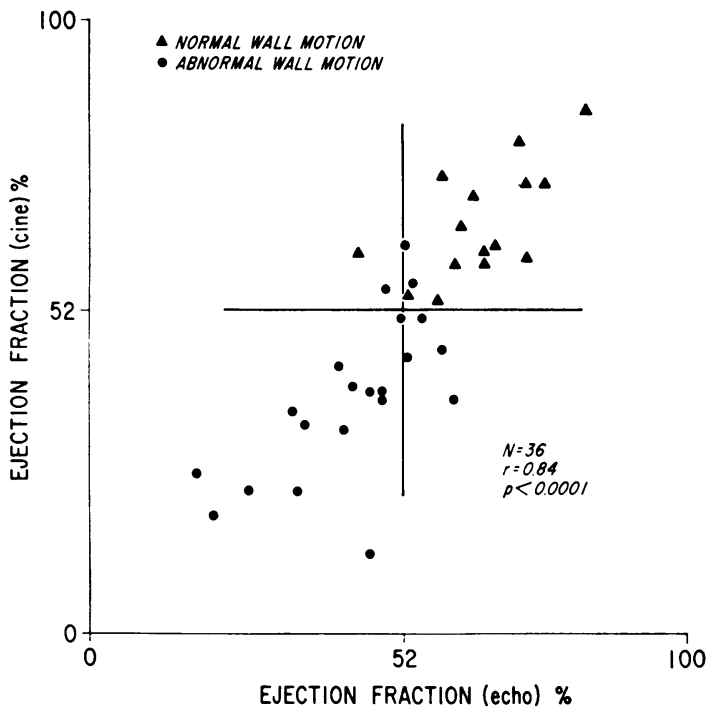

FIG. 3 Ejection fraction calculated by cineangiography is well correlated with ejection fraction derived from echocardiography. The crossed lines depict the lower limit of normal for ejection fraction (Kennedy et al., 1966).

patient group, there was a highly significant correlation between the echo and cine measurements of ejection fraction $(r=0.84, P<0.0001)$.

\section{Mean rate of circumferential fibre shortening (mean $\mathbf{V}_{\mathrm{CF}}$ )}

For the 15 patients with normal wall motion, mean $\mathrm{V}_{\mathrm{CF}}$ measured by echo averaged $\mathrm{I} \cdot 26 \pm 0 \cdot 24 \mathrm{circ} / \mathrm{sec}$, and by cine $\mathrm{r} \cdot 64 \pm 0.55 \mathrm{circ} / \mathrm{sec}$. For the $2 \mathrm{I}$ patients with abnormal wall motion, echo mean $\mathrm{V}_{\mathrm{CF}}$ averaged $0.67 \pm 0.2 \mathrm{I} \mathrm{circ} / \mathrm{sec}$, and cine mean $\mathrm{V}_{\mathrm{CF}}$ averaged $0.65 \pm 0.23 \mathrm{circ} / \mathrm{sec}$ (Table, Fig. 4). All patients with wall motion abnormalities had depressed left ventricular performance as judged by mean $V_{C F}$ calculated either by cineangiography or by echocardiography. Similarly, in patients with normal wall motion, both echo and cine estimates of mean $\mathrm{V}_{\mathrm{CF}}$ were in good agreement, with the exception of 3 patients. The 2 patients depicted in the right lower quadrant of Fig. 4 both had billowing posterior mitral leaflets.

\section{Discussion}

For conventional echocardiographic measurement of left ventricular volume and ejection fraction, the end-diastolic and end-systolic distances between the opposing endocardial surfaces of the interventricular septum and posterior wall immediately

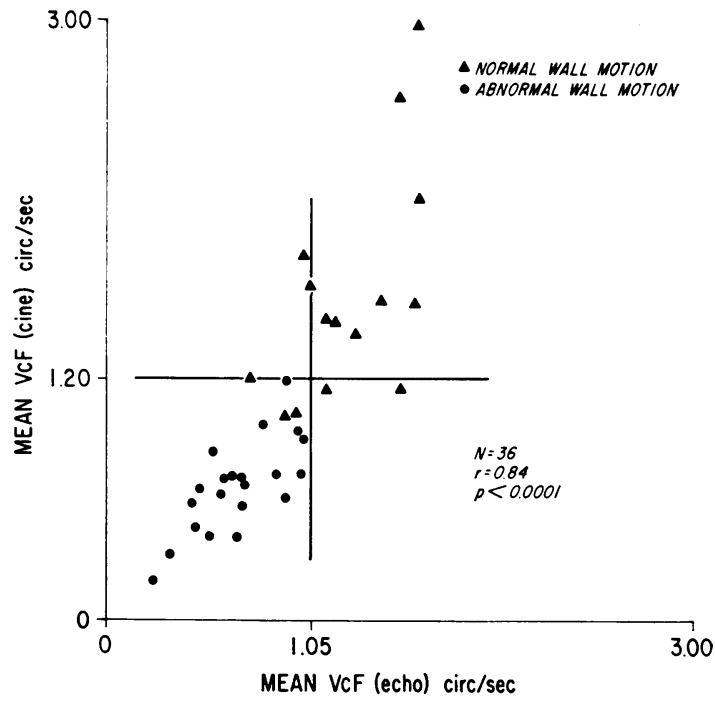

FIG. 4 Mean $V_{C F}$ derived by cineangiography is plotted against mean $V_{C F}$ calculated by echocardiography. A highly significant correlation is apparent. The crossed lines represent the lower limits of normal for each measure (Cooper et al., 1972).

inferior to the mitral valve plane are cubed (Pombo et al., 197I). Two basic assumptions underlie this technique: first, it is assumed that the motion of the 2 small loci of left ventricular wall sampled by the ultrasound beam is representative of the entire chamber; second, that the longitudinal apex-tobase dimension of the left ventricle is twice the minor dimension. In the normal human left ventricle, these assumptions are valid and therefore this technique provides a reliable assessment of left ventricular volume, which correlates significantly with cineangiographic calculations (Pombo et al., 1971; Cooper et al., 1972). In the chamber with an abnormal shape or pattern of wall motion, however, it is apparent that either one or both of these basic assumptions may not be valid, since the varying distribution of segmental wall changes throughout the ventricle may render the areas sampled by the ultrasound beam unrepresentative of the remainder of the chamber. Further, as it dilates, the left ventricle becomes more spherical, so that the theoretical geometric models on which the cube formulae are based are no longer applicable.

Our data indicated that measurements of enddiastolic volume by ultrasound are most subject to error when there is anterior wall dyskinesis or when the left ventricular cavity is obviously dilated (Fig. 2). However, correlation between the ultra- 
sound and cine measurements remained highly significant even when only those patients with wall motion disorders were considered (Table, Fig. 2). Further, in comparison with the cineangiographic measurement, the echo technique retained its ability to separate normal from increased left ventricular volume, though greater scatter was observed in patients with abnormal wall motion.

Despite these inaccuracies in the single measurement of end-diastolic volume, however, it should be emphasized that similar, and in most instances proportionate, deviations in end-systolic volume occurred. Thus, the calculated relation between end-diastolic and end-systolic volumes, i.e. the ejection fraction, correlated significantly with the cineangiographic measurements. Furthermore, when the time factor of ejection was taken into account, as in the calculation of mean $\mathrm{V}_{\mathrm{CF}}$, very close correlation with the cineangiographic estimate was found, and the ability to distinguish normal from impaired left ventricular function became quite accurate. This finding is in keeping with previous reports from this laboratory, in which mean $V_{C F}$ has proved a reliable means of distinguishing normal from reduced left ventricular performance (Karliner et al., I97I; Cooper et al., 1972). It is of interest that 2 patients with apparently normal wall motion, in whom mean $\mathrm{V}_{\mathrm{CF}}$ was reduced both by cine and by echo, had billowing posterior mitral leaflets. In the presence of the latter, a decreased extent and rate of circumferential fibre shortening in the proximal ventricular segment have recently been reported (Leidtke et al., 1973).

Thus, though isolated measurements of enddiastolic volume may be erroneous in the presence of wall motion disorders, it appears that use of derived ejection phase indices of left ventricular performance, particularly mean $\mathrm{V}_{\mathrm{CF}}$, remain highly accurate, both in their ability to separate patients with normal from those with impaired left ventricular function, and in their degree of correlation with cineangiographic measurements. This finding may be explicable on the basis of two empirical echographic observations: first, when the excursion of one of the ventricular walls is reduced, some compensation is frequently provided by increased excursion of the opposing wall, so that any error introduced by measurement of the movement of one wall is cancelled by that of the other; second, in patients with wall motion abnormalities, internal shortening velocity measured between the septum and the posterior wall tends to be representative of total left ventricular performance, while isolated disorders of wall movement in areas not traversed by the ultrasound beam usually are not sufficiently large to produce important alterations in left ventricular function. Further, calculation of mean $V_{C F}$ does not require any assumptions regarding left ventricular size or shape, while cubing the measured dimension, as in the calculation of left ventricular volume and ejection fraction, will tend to exaggerate errors introduced by the assumption that there is a fixed ratio between the major and minor axes of the left ventricular chamber.

Our results are consistent with the data recently reported by Gibson (1973) who noted a highly significant correlation between cineangiographic and echocardiographic estimations of left ventricular volume. Though Gibson studied only 4 patients with abnormalities of wall motion due to coronary artery disease, he cautioned that in such patients the echocardiographic method required further substantiation. Our data indicate that ultrasound assessment of left ventricular function, while exhibiting highly significant group correlations with cineangiographic estimations in patients with left ventricular wall motion disorders, may be subject to some error in individual patients. However, calculations of ejection phase measures of performance, especially mean $\mathrm{V}_{\mathrm{CF}}$, appear to be valid even in the presence of abnormal left ventricular wall motion.

\section{References}

Cooper, R. H., O'Rourke, R. A., Karliner, J. S., Peterson, K. L., and Leopold, G. R. (1972). Comparison of ultrasound and cineangiographic measurements of the mean rate of circumferential fiber shortening in man. Circulation, 46, 914 .

Dodge, H. T., Sandler, H., Ballew, D. W., and Lord, J. D. (1960). The use of biplane angiocardiography for the measurement of left ventricular volume in man. American Heart fournal, 60, 762.

Dodge, H. T., Sandler, H., Baxley, W. A., and Hawley, R. R. (I966). Usefulness and limitations of radiographic methods for determining left ventricular volume. American fournal of Cardiology, 18, 10.

Gibson, D. G. (1973). Estimation of left ventricular size by echocardiography. British Heart fournal, 35, 128.

Karliner, J. S., Gault, J. H., Eckberg, D., Mullins, C. B., and Ross, J., Jr. (197I). Mean velocity of fiber shortening: a simplified measure of left ventricular myocardial contractility. Circulation, 44, 323.

Kennedy, J. W., Baxley, W. A., Figley, M. M., Dodge, H. T., and Blackmon, J. R. (I966). Quantitative angiocardiography. I. The normal left ventricle in man. Circulation, $34,272$.

Leidtke, A. J., Gault, J. H., Leaman, D. M., and Blumenthal, M. S. (1973). Geometry of left ventricular contraction in the systolic click syndrome: characterization of a segmental myocardial abnormality. Circulation, 47, 27.

Pombo, J. F., Troy, B. L., and Russell, R. O., Jr. (1971). Left ventricular volumes and ejection fraction by echocardiography. Circulation, 43, 480. 
Popp, R. L., Alderman, E. L., Brown, O. R., and Harrison. D. C. (1973). Sources of error in calculation of left ventricular volumes by echography (abstract). American fournal of Cardiology, 31, I52.

Popp, R. L., Wolfe, S. B., Hirata, T., and Feigenbaum, H. (I969). Estimation of right and left ventricular size by ultrasound. American fournal of Cardiology, 24, 523.

Teichholz, L. E., Kreulen, T. H., Herman, M. V., and
Gorlin, R. (1972). Problems in echoçardiographic volume determinations: echo-angiographic correlations (abstract). Circulation, 46, Suppl. II, 75.

Requests for reprints to Dr. R. A. O'Rourke, University Hospital of San Diego County, 225 West Dickinson Street, San Diego, California 92 ro3, U.S.A. 